\title{
The effect of lexical stratum on perception of contrast
}

\section{Jiwon Hwang, Yu-an Lu, Jennifer Park, Jessica Fareri, Ellen Broselow, and Marie Huffman}

Stony Brook University (SUNY)

Much research has established that speech perception is affected by the phonological structure of the listener's native language. This paper investigates how perception is affected by coexisting phonological systems within a single language.

The Japanese lexicon is generally characterized as consisting of distinct strata, with each stratum subject to distinct sets of phonological restrictions (Itô \& Mester 1995, 1999; Moreton, Amano, and Kondo 1998). For example, singleton [p] occurs only in foreign-origin vocabulary (peepaa 'paper'), while [hj] onsets occur only in native vocabulary. Two sets of experiments have suggested that Japanese speakers' perceptual boundaries can be affected by cues to stratal affiliation. Moreton and Amano (1999) investigated Japanese listeners' categorization of nonwords of the form $\operatorname{CoCA}$, where $A$ indicates a vowel that was ambiguous between short [a] (which occurs in both native and foreign-origin words) and long [a] (restricted to foreign-origin vocabulary). They found that listeners were more likely to identify the nonword as $\mathrm{CoCa}$ when the context contained cues indicating foreign origin, and as $\mathrm{CoCa}$ when the context contained native-specific cues. Gelbart and Kawahara (2007) found similar effects from knowledge of lexical affiliation, even in the absence of phonological cues. Japanese speakers presented with nonwords created by lengthening final [a] in foreign-origin words (such as nasa 'NASA') and native words (such as mosa 'tough guy') were more likely to categorize the final vowel as long in the stimuli formed from foreign words. Thus, knowledge of stratal affiliation affected category boundaries, even when the context contained no overt phonological cues to stratum membership.

Our study was designed to determine whether stratal cues affect not only the categorization of ambiguous stimuli but also the ability to discriminate sounds. We focused on Japanese native speakers' ability to discriminate two contrasts: /ti/ vs. /t $\mathrm{i} /$ and /si/ vs. / $\mathrm{i} /$. In native strata, where both $/ \mathrm{t} /$ and $/ \mathrm{s} /$ are palatalized before $/ \mathrm{i} /$, neither pair is contrastive (Itô \& Mester 1995: /kat+i/>katfi 'win, inf.'; /hanas $+\mathrm{i} />$ hanafi 'talk, inf.'). However, /ti/ sequences are maintained in many foreign-origin words, e.g.jitibay ku 'Citibank' (Itô \& Mester 1995, Crawford 2007, Shaw 2007, Shaw \& Balusu 2010), giving rise to the possibility of /ti-t $\mathrm{fi} /$ contrasts. Therefore, /ti/ and /t $\mathrm{fi} /$ may contrast in foreign-origin but not native strata, while $/ \mathrm{si} /$ and $/ \mathrm{Ji} /$ contrast in neither foreign-origin nor native vocabulary.

If stratal context affects discrimination, Japanese NSs should discriminate / $\mathrm{ti}-\mathrm{t} \mathrm{fi} / \mathrm{more}$ successfully in foreign-cueing than in native-cueing contexts, but should discriminate /si-ji/ equally poorly in both contexts. However, if listeners maintain a single perceptual system sensitive to all possible contrasts of the language, we expect better performance on /ti-t $\mathrm{ti}$ / than on /si-ji/ for Japanese listeners, in both contexts. We tested this using an ABX discrimination task in which 14 Japanese NSs in Japan and 25 English NSs in the US were presented with nonce triplets of trisyllabic stimuli, e.g. hjatire-hjatfire-hjatire, produced by a bilingual JapaneseEnglish speaker. In each triplet, the initial syllable was either hja (native) or $f a$ (foreign). The second syllable tested discrimination of either /si- $-\mathrm{i} /$ or $/ \mathrm{ti}-\mathrm{t} \mathrm{i} /$, and the third syllable was appropriate for either stratum.

As expected, Japanese listeners performed significantly better in discriminating /ti ///t $\mathrm{j} /$ than $/ \mathrm{si}-\mathrm{j} \mathrm{i} /$ in the foreign stratum. However, this effect held across both stratal contexts: even in the native stratum, where neither contrast is possible, /ti-t $\mathrm{i}$ / was still discriminated more 
successfully than /si-fi/. The presence of stratum-specific contextual cues did not significantly affect the Japanese speakers' ability to discriminate either contrast. Furthermore, the English controls, for whom both sets of sounds are contrastive, showed (like the Japanese NSs) significantly better discrimination of /ti $/-/ \mathrm{t} \mathrm{i} /$ than of $/ \mathrm{si}-\mathrm{j} \mathrm{i} /$.

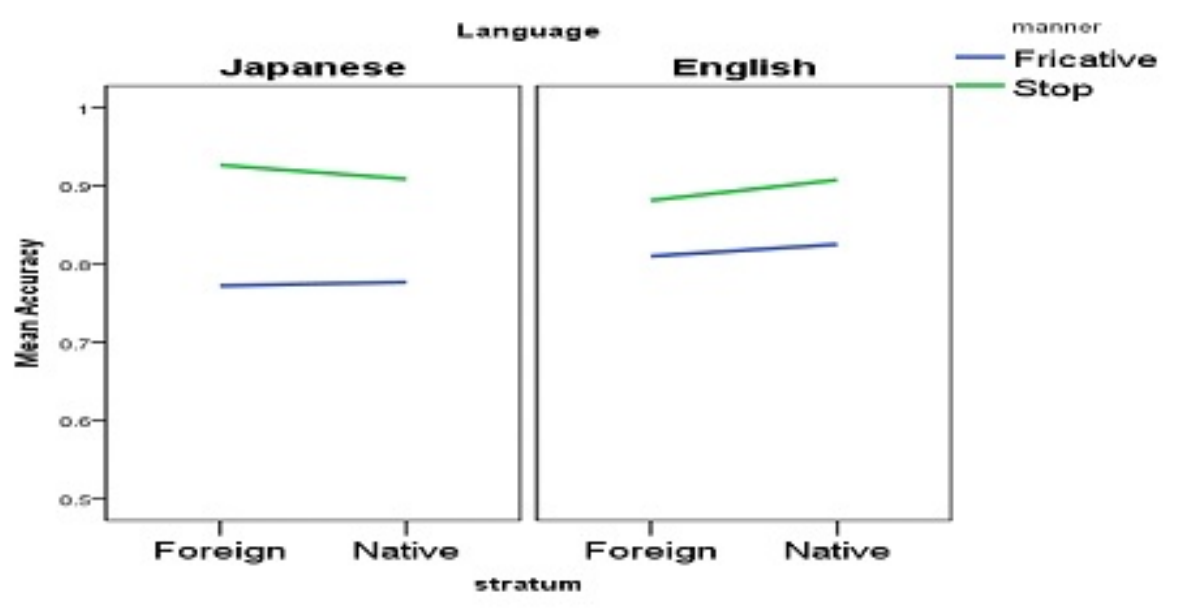

These results raise two questions: (1) Why did the Japanese speakers exhibit no effect of contextual cues to stratum (contra the findings of Moreton and Amano 1999 and Gelbart and Kawahara 2007)? (2) Why did the English speakers have greater difficulty discriminating /si-fi/ than $/ \mathrm{ti}-\mathrm{t} \mathrm{i} /$ when both pairs are contrastive in English?

The lack of a stratum effect in this experiment, as opposed to the earlier experiments, may stem from several differences in experimental design. First, while the earlier experiments investigated a durational contrast, this experiment involved differences in place and manner. Perhaps more important, however, is the experimental task: the earlier studies involved categorization of ambiguous stimuli, while this experiment involved discrimination of two ends of a continuum. It seems likely, therefore, that the discrimination task involved auditory processing, while the earlier categorization tasks may have tapped into a phonological level. The fact that speakers could discriminate two sounds even in contexts in which the sounds would not be contrastive suggest that once a speaker has learned to discriminate a contrast, this discrimination cannot be 'turned off', even where it is not relevant. This finding is consistent with findings from literature on second language acquisition for cases in which learning requires the suppression of native language contrasts; for example, Escudero and Boersma (2002) present evidence that beginning learners of Dutch tend to incorrectly perceive the Spanish 2-way /i-e/ contrast in terms of the three Dutch categories corresponding to this vowel space.

The second finding that requires explanation is the fact that even English listeners, for whom both contrasts are significant, were more successful in discriminating / $\mathrm{ti}-\mathrm{t} \mathrm{\textrm {i }} / \mathrm{than} / \mathrm{si}-\mathrm{j} \mathrm{i} /$. To determine whether the /si/ and / $\mathrm{i} /$ stimuli produced by our Japanese-English bilingual were simply less English-like than the same speaker's / $\mathrm{ti} /$ and $/ \mathrm{t} \mathrm{i}$ / (see Li et al. 2009; Li et al. in press on the acoustics of the Japanese and English fricatives), we conducted a second experiment in which 16 native speakers of English were presented with the nonwords from the first experiment (e.g. hjatire, hjatyire, hjasire, hja fire) alongside the same words produced by a native speaker of English. Participants were asked to identify the middle consonant of each nonword and to supply a goodness rating for that consonant. We found no significant effect of speaker (bilingual vs. 
native) on identification accuracy, and no difference in goodness ratings for $/ \mathrm{s} /$ and $/ \mathrm{t} /$. While the bilingual speaker's $/ \mathrm{t} /$ and $/ \mathrm{J} /$ were rated significantly lower than those of the native speaker, the ratings of these two sounds were not significantly different from each other, suggesting that this speaker's / $/$ was no less acceptable to English speakers than her $/ \mathrm{t} /$. We conclude, then, that the / $\mathrm{i}-\mathrm{t} \mathrm{t} \mathrm{i} /$ contrast is simply inherently more distinguishable than the /si- $\mathrm{j} \mathrm{i} /$ contrast. This finding helps to explain the fact that [ti] was adopted into Japanese fairly early (Crawford 2007), while [si] has still not become established, as illustrated by loans like Sitibanku 'Citibank' (Itô and Mester 1995). Even with equal exposure to [ti] and [si], it would presumably take longer for Japanese speakers to recognize that the latter sequence is distinct from a native language sequence, delaying the introduction of this new structure into their phonological system.

\section{References}

Crawford, Clifford. 2007. An evolutionary account of loanword-induced sound change in Japanese. U. Penn Working Papers in Linguistics 10, 1-14.

Escudero, Paola and Paul Boersma. 2002. The subset problem in L2 perceptual development: multiple-category assimilation by Dutch learners of Spanish. In. B. Skarabela, S. Fish, \& A. H.-J. Do (eds.), Proceedings of the $26^{\text {th }}$ Annual Boston University Conference on Language Development, 208-219. Somerville, MA: Cascadilla Press.

Gelbart, Ben and Shigeto Kawahara. 2007. Lexical cues to foreignness in Japanese. Proceedings of Formal Approaches to Japanese Linguistics 4, 55-67.

Itô, Junko and Armin Mester. 1995. Japanese phonology. In J. Goldsmith (ed.) The Handbook of Phonological Theory, 817-838. Cambridge, MA: Blackwell Publishers Ltd.

Itô, Junko and Armin Mester. 1999. The phonological lexicon. In N. Tsujimura (ed.) The Handbook of Japanese Linguistics, 62-100. Malden, MA: Blackwell Publishers Ltd.

Li, Fangfang, Jan Edwards, and Mary Beckman. 2009. contrast and covert contrast: The phonetic development of voiceless sibilant fricatives in English and Japanese toddlers. Journal of Phonetics 37, 111-124.

Li, Fangfang, Benjamin Munson, Jan Edwards, Kiyoko Yoneyama, and Kathleen Hall. In press. Language specificity in the perception of voiceless sibilant fricatives in Japanese and English: Implications for cross-language differences in speech-sound development. Journal of the Acoustical Society of America.

Moreton, Elliot and Shigeaki Amano. 1999. The effect of lexical stratum phonotactics on the perception of Japanese vowel length. Proceedings of the 6th European Conference on Speech Communication and Technology.

Moreton, Elliot, Shigeaki Amano, and Tadahisa Kondo. 1998. Statistical phonotactics of Japanese: transitional probabilities within the word. Transaction of the Technical Committee on Psychological and Physiological Acoustics, H-09-120, 63-70.

Shaw, Jason. 2007. /ti/-/t $\mathrm{i} /$ contrast preservation in Japanese loans parasitic on segmental cues to prosodic structure. ICPhS XVI, 1365-1368.

Shaw, J.A. and R. Balusu. 2010. Language contact and phonological contrast: the case of coronal affricates in Japanese loans. In Norde, Muriel, Bob de Jonge, and Cornelius Hasselblatt (eds.) Language Contact: New Perspectives. Studies in Language and Society 28. Amsterdam: John Benjamins. 